\title{
Stress Analysis of a Maxillary Central Incisor Restored with Different Posts
}

\author{
Necdet Adanira, DDS, PhD \\ Sema Bellib, DDS, PhD
}

\begin{abstract}
Objectives: To evaluate the effects of different post materials on the stress distribution in an endodontically treated maxillary incisor.

Materials and Methods: A pseudo 3-dimensional finite element model was created in a labiolingual cross-sectional view of a maxillary central incisor and modified according to five posts with different physical properties consisting stainless steel, titanium, gold alloy, glass fiber (Snowpost), and carbon fiber (Composipost). A $200 \mathrm{~N}$ force was then applied from two different directions; al vertical load on the incisal edge, b) 45 degree diagonal load above the cingulum location. Stress distribution and values were then calculated by considering the pseudo three dimensional von Mises stress criteria.

Results: Under two loading conditions, post made of steel showed greatest stress concentration at the post/dentin interface followed by titanium, gold alloy, Snowpost and Composipost. However, Composipost, which elastic modulus was closer to the dentin, produced highest stress values at $1 / 3$ cervical area.

Conclusions: Within the limitation of this simulated mechanical analysis, we can conclude that the physical characteristics of posts were important on stress distributions in post and core applications. Glass fiber post revealed more balanced stress distribution under functional forces. (Eur J Dent 2007;2:67-711
\end{abstract}

Key Words: Stress analysis; Finite element method; Endodontically treated teeth; Fiber post; Metal post,

\section{INTRODUCTION}

Endodontically treated teeth are generally weakened as a result of structure loss due to decay, previous restorative procedures and end-

$\square$ a Assistant Professor, Department of Endodontics, Faculty of Dentistry, University of Suleyman Demirel.

${ }^{b}$ Professor, Department of Endodontics,

Faculty of Dentistry, University of Selcuk.

$\square$ Corresponding Author: Dr. Necdet Adanir Suleyman Demirel Universitesi, Dishekimligi Fakultesi Endodonti Anabilim Dali Dogu Kampusu 32260 Isparta, Turkey.

Tel: +902462113287 Fax: +90 2462370607

E-mail: necdetadishek.sdu.edu.tr

odontic access preparation. To prevent further destruction of these teeth, a protective restoration is necessary to create retention and resistance. ${ }^{1} \mathrm{~A}$ widely used method for treatment of structurally weakened teeth is the post and core system. The primary objective of post and core procedure is replacement of the lost tooth structures in order to facilitate crown support and retention. ${ }^{2}$

There are various post and core systems. The most widely used systems can be classified into two basic types; metal posts and cores that are custom cast as a single piece, and two element designs comprising a prefabricated post to which a 
silver amalgam or composite core is subsequently adapted. The construction at post-core castings is relatively more time consuming and demands extra clinic and laboratory time and in addition costs more. ${ }^{3}$ Prefabricated posts allow fast, cheap and easy techniques to be used in the restoration of endodontically treated teeth. ${ }^{4,5}$

Stress distribution analysis of prefabricated post applications has been studied by many researchers using different theoretical or experimental techniques. ${ }^{6-9}$ Finite element analysis (FEA) has become a popular numerical method in stress analysis and has been applied to dental biomechanics for last decades. ${ }^{10,11}$ FEA method is based on a mathematical model which approximates the geometry and the loading conditions of the structure to be analyzed. Deformation and stress distributions in response to different loading conditions can be simulated with the aid of computers and the most stressed areas can thus be evidenced. ${ }^{12}$

The purpose of this study was to evaluate the effects of different post materials on the stress distribution in maxillary central incisor with FEA. The null hypothesis was that there was no association between the mechanical properties of post materials and stress distribution.

\section{MATERIALS AND METHODS}

In this study, a pseudo 3-dimensional finite element model was created in a labiolingual crosssectional view of a maxillary central incisor with its supporting structures. The geometry used for the tooth model was described by Wheeler. ${ }^{13}$ The model was modified according to five posts with different physical properties consisting stainless steel, titanium, gold alloy, glass fiber (Snowpost, Carbotech, Ganges, Francel and carbon fiber (Composipost, Recherches Techniques Dentaires (RTD), Saint-Egrève, France). For each model, post length was designed $9 \mathrm{~mm}$ inside the root canal. Each mathematical model included 2672 elements and 2533 nodes. All of the materials were treated as homogenous, isotropic and linear elastic. The material properties of the various simulated components were assigned according to literature data (Table 1). ${ }^{14-16}$ Because of its low thickness, the effect of bonding cements was neglected. The final element on the $-X$ and $-Y$ axis for each model was assumed to be fixed for boundary conditions. As a $-Z$ axis, a $1 \mathrm{~mm}$ section was added and a pseudo third dimension was created. A $200 \mathrm{~N}$ force was then applied from two different directions; al vertical load on the incisal edge (node 2466), b) 45 degree diagonal load above the cingulum location (node 188).

Compaq Presario 1505 US computer and SAP2000 software (v7.12, Computer Structures Inc, Berkeley, USAl were used for the stress analysis. Stress distribution and stress values were then calculated by considering the pseudo three dimensional von Mises stress criteria.

\section{RESULTS}

The stress conditions in the system were analyzed for five types of post; stainless steel, titanium, gold alloy, glass fiber and carbon fiber. When a vertical force applied, the maximum values of stress were recorded at the post and dentin buccal interface except carbon fiber post model. In the carbon fiber post, mathematical model was evaluated and stress was accumulated at 1/3 buccal cervical area (Figure 1a). The maximum stress value within root was recorded at dentin buccal interface in the stainless steel post model (Figure $1 b)$. On the contrary, the minimum stress values were observed at cervical palatal root region for metal posts (Figure 1c).

When 45 degree diagonal loading applied above the cingulum location, stress accumulation at mid-upper buccal dentin were increased respectively in stainless steel, titanium, gold alloy, glass fiber and carbon fiber post designs (Figure 2). When the elastic modulus of the post was increased, stress accumulation along the cervical

Table 1. Elastic modulus and Poisson's ratio of materials.

\begin{tabular}{lcc}
\hline Material & $\begin{array}{c}\text { Elastic Modulus } \\
\text { (MPa) }\end{array}$ & Poisson's Ratio \\
\hline Stainless steel & 200000 & 0.33 \\
Titanium alloy & 104000 & 0.33 \\
Gold alloy & 89500 & 0.33 \\
Glass fiber (Snowpost) & 45000 & 0.28 \\
Carbon fiber (Composipost) & 22000 & 0.31 \\
Photocore & 18600 & 0.26 \\
Dentin & 18000 & 0.31 \\
Cortical bone & 13700 & 0.3 \\
Sponge bone & 1370 & 0.3 \\
Gutta-percha & 0.69 & 0.45 \\
Gingiva & 0.019 & 0.3 \\
Periodontal ligament & 0.5 & 0.45 \\
\hline
\end{tabular}


$1 / 3$ post and dentin interface was intensified (Figure $2 \mathrm{a}$ ). Compared with the values at the cervical area, the stress in mid-upper buccal dentin along the root was higher than others when carbon fiber post model evaluated (Figure $2 b$ ).

\section{DISCUSSION}

Post-core application components create unnatural stress distributions because it fills the root canal space with a material that has a defined stiffness unlike the soft pulp tissue. All structural analysis of post-core components of a restoration can give some understanding into the direction of forces playing on the restoration and tooth structure. In the literature, different methods have been reported for evaluating the mechanical behavior of post and core in tooth restoration. FEA method has been used and shown to be a useful tool when investigating complex systems that are difficult to standardize during in vitro and in vivo studies.

In the present study, using FEA method, the effect of post application on stress amount and distribution under functional forces was evaluated. According to the results of this study, the mechanical properties of the post material affected stress distribution. Thus, the null hypothesis that variation of the parameters would not affect stress distribution was rejected.

The results of FEA clearly demonstrated that when vertical or diagonal force applied, the peak stress values were observed at force application point. Comparing the peak stresses at the post-dentin interface, stainless steel post generated more stress accumulation than others.

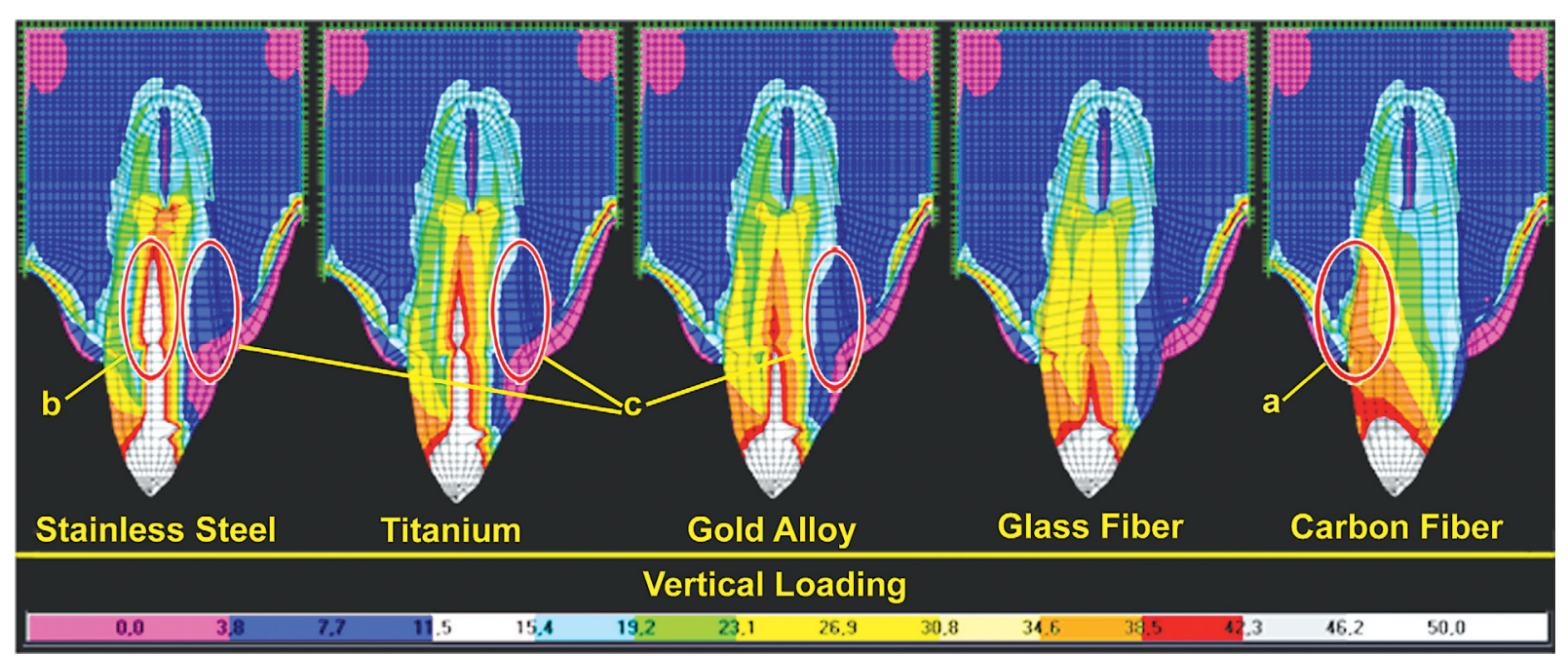

Figure 1. Distribution of von Mises stresses ( $\mathrm{MPa}$ ) when vertical loading was applied. Areas with same color were subjected to same range of stresses, as shown by numbers to bottom of colored rectangles; al stress was accumulated at $1 / 3$ buccal cervical area, b) the maximum stress value within dentin buccal interface in the stainless steel post model, cl the minimum stress values at cervical palatal root region for metal posts.

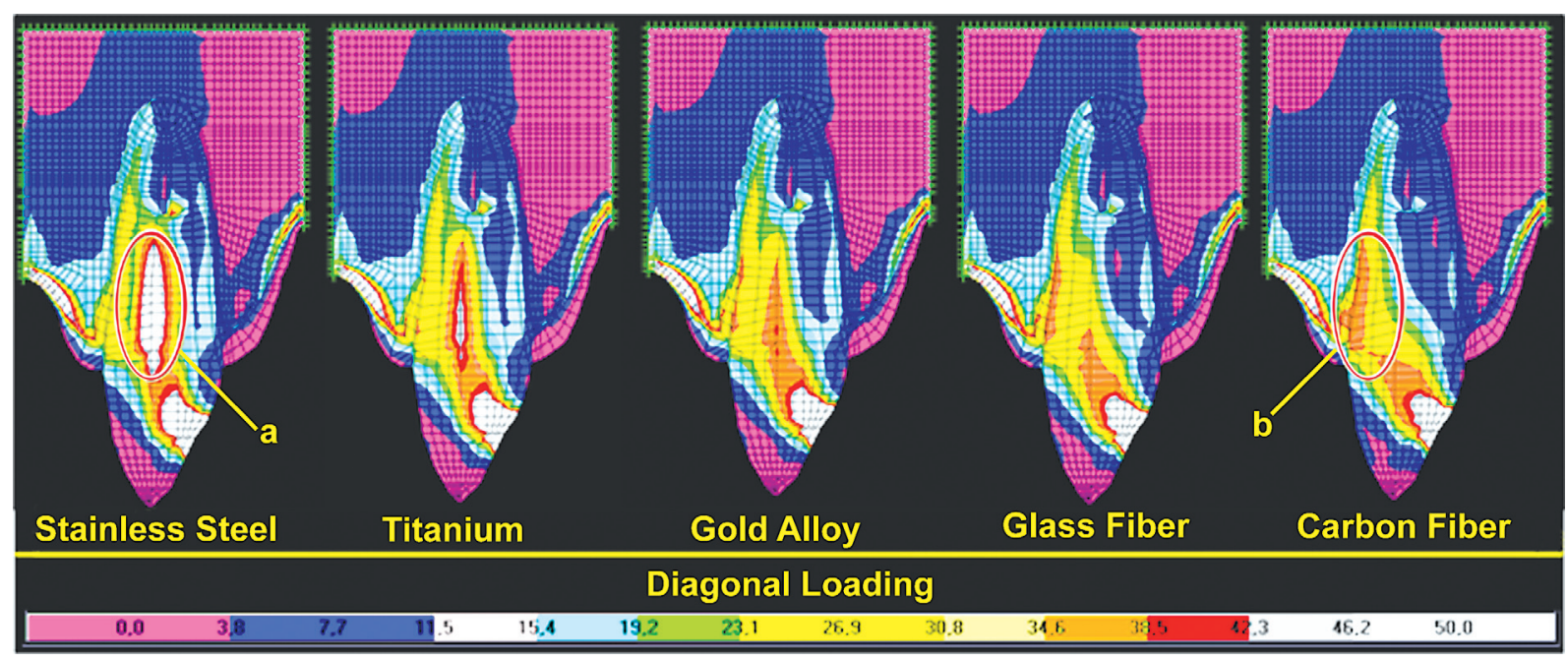

Figure 2. Diagram of Von Mises stress distribution when diagonal force was applied. al stress accumulation along the cervical 1/3 post and dentin interface, b) stress distribution in mid-upper buccal dentin in carbon fiber post model. 
These results are in agreement with a previous study. ${ }^{17}$ Lanza et al ${ }^{17}$ reported that even working on the cement layer, stress absorbing capability by using less rigid cements was not possible to improve the stress arising in the system because of the high rigidity of the steel post. They also reported that glass reconstruction system produced the most benign stressing condition. This result agreed with our study in which glass fiber post (Snowpost elastic modulus is $45000 \mathrm{MPa}$ ) model showed more balanced stress distribution at post and dentin interface and cervical area. In another FEA study, Boschian Pest et $\mathrm{al}^{18}$ reported that fiberglass-reinforced composite distributed stress better than titanium alloy or stainless steel post. These results also agreed with the present study. They observed that the maximum stress values were generated by the metal post. In the present study, widely stress value generated by stainless steel post was monitored at the post-dentin interface.

For each model used in this study, post length was designed $9 \mathrm{~mm}$ inside the root canal. In an in vivo study, it was reported that teeth restored with $9 \mathrm{~mm}$ carbon fiber post showed a significantly higher 4 years survival rate than teeth restored with metal cast post-core. ${ }^{19}$ This finding corroborated the results of our study. In present study, carbon fiber post (Composipost) produced minimum values at post-dentin interface. According to Cailleteau et $\mathrm{al}^{20}$ the stress magnitude on the dentin-post interface is important because it can be associated to dentin crack initiation or even dentin fracture.

In this study, the effect of cement layer was neglected because of its low thickness. However, a previously reported study revealed that the cement with elastic modulus similar to dentin could reinforce weakened root and reduce the stress in dentin. ${ }^{21}$ It was the weakness of this study that thin cement layer was not designed.

\section{CONCLUSIONS}

Within the limits of this in vitro study, it can be concluded that;

- The physical properties of posts were important on stress distributions in post and core applications,

- Glass fiber post revealed more balanced stress distribution under functional forces,
- It is possible to change the stress distribution at the cervical region or internal root structure by using different post core materials.

\section{REFERENCES}

1. Plasmans PJ, Welle PR, Vrijhoef MM. In vitro resistance of composite resin dowel and cores. J Endod 1988;14:300304.

2. Cohen S, Burns CB. Pathways of the pulp. 7th ed. St. Louis: CV Mosby, 1998:691-717.

3. DeSort KD. The prosthodontic use of endodontically treated teeth: theory and biomechanics of post preparation. $J$ Prosthet Dent 1983;49:203-206.

4. Kern SB, von Fraunhofer JA, Mueninghoff LA. An in vitro comparison of two dowel and core techniques for endodontically treated molars. J Prosthet Dent 1984;51:509-514.

5. Hudis SI, Goldstein GR. Restoration of endodontically treated teeth: a review of the literature. J Prosthet Dent 1986;55:33-38.

6. Peters MC, Poort HW, Farah JW, Craig RG. Stress analysis of a tooth restored with a post and core. $J$ Dent Res 1983;62:760-763.

7. Leary JM, Jensen ME, Sheth JJ. Load transfer of posts and cores to roots through cements. J Prosthet Dent 1989;62:298-302.

8. Loney RW, Kotowicz WE, McDowell GC. Three-dimensional photoelastic stress analysis of the ferrule effect in cast post and cores. J Prosthet Dent 1990;63:506-512.

9. Standlee JP, Caputo AA. The retentive and stress distributing properties of split threaded endodontic dowels. J Prosthet Dent 1992;68:436-442.

10. Farah JW, Craig RG, Sikarskie DL. Photoelastic and finite element stress analysis of a restored axisymmetric first molar. J Biomech 1973;6:511-520.

11. Thresher RW, Saito GE The stress analysis of human teeth. J Biomech 1973;6:443-449.

12. Zienkiewicz OC. The finite element method. London UK: McGraw-Hill, 1986.

13. Wheeler RC. Dental anatomy physiology and occlusion. London: WB Saunders, 1984.

14. Ko CC, Chu CS, Chung KH, Lee MC. Effects of posts on dentin stress distribution in pulpless teeth. J Prosthet Dent 1992;68:421-427.

15. Holmes DC, Diaz-Amold AM, Leary JM. Influence of post dimension on stress distribution in dentin. J Prosthet Dent 1996;75:140-147.

16. Yaman SD, Alacam T, Yaman Y. Analysis of stress distribution in a maxillary central incisor subjected to various post and core applications. J Endod 1998; 24:107-111.

17. Lanza A, Aversa R, Rengo S, Apicella D, Apicella A. 3D FEA 
of cemented steel, glass and carbon posts in a maxillary incisor. Dent Mater 2005;21:709-715.

18. Boschian Pest L, Guidotti S, Pietrabissa R, Gagliani M. Stress distribution in a post-restored tooth using the three-dimensional finite element method. J Oral Rehabil 2006;33:690-697.

19. Ferrari M, Vichi A, Garcia-Godoy F. Clinical evaluation of fiber-reinforced epoxy resin posts and cast post and cores. Am J Dent 2000;13:15B-8B.

20. Cailleteau JG, Rieger MR, Akin JE. A comparison of intracanal stresses in a post-restored tooth utilizing the finite element method. J Endod 1992;18:540-544.

21. Li LL, Wang ZY, Bai ZC, Mao Y, Gao B, Xin HT, Zhou B, Zhang Y, Liu B. Three-dimensional finite element analysis of weakened roots restored with different cements in combination with titanium alloy posts. Chin Med J (Engl) 2006;119:305-311. 